\title{
Artificial Intelligence and the Future of Psychiatry: Insights from a Global Physician Survey
}

P. Murali Doraiswamy ${ }^{1,2}$, Charlotte Blease ${ }^{3}$, Kaylee Bodner ${ }^{1}$

Departments of Psychiatry and Behavioral Sciences ${ }^{1}$ and Medicine ${ }^{2}$, Duke University School of Medicine

Department of General Medicine and Primary Care ${ }^{3}$, Beth Israel Deaconess Medical Center, Harvard Medical School, School of Psychology ${ }^{3}$, University College Dublin

Correspondence to:

Professor Murali Doraiswamy, DUMC Box-3018, Durham, NC 27710, USA 


\begin{abstract}
Background: Futurists have predicted that new autonomous technologies, embedded with artificial intelligence $(\mathrm{Al})$ and machine learning $(\mathrm{ML})$, will lead to substantial job losses in many sectors disrupting many aspects of healthcare. Mental health appears ripe for such disruption given the global illness burden, stigma, and shortage of care providers.
\end{abstract}

Objective: To characterize the global psychiatrist community's opinion regarding the potential of future autonomous technology (referred to here as $\mathrm{Al} / \mathrm{ML}$ ) to replace key tasks carried out in mental health practice.

Design: Cross sectional, random stratified sample of psychiatrists registered with Sermo, a global networking platform open to verified and licensed physicians.

Main outcome measures: We measured opinions about the likelihood that $\mathrm{Al} / \mathrm{ML}$ tools would be able to fully replace - not just assist - the average psychiatrist in performing 10 key psychiatric tasks. Among those who considered replacement likely, we measured opinions about how many years from now such a capacity might emerge. We also measured psychiatrist's perceptions about whether benefits of Al/ML would outweigh the risks.

Results: Survey respondents were 791 psychiatrists from 22 countries representing North America, South America, Europe and Asia-Pacific. Only 3.8\% of respondents felt it was likely that future technology would make their jobs obsolete and only $17 \%$ felt that future $\mathrm{Al} / \mathrm{ML}$ was likely to replace a human clinician for providing empathetic care. Documenting and updating medical records (75\%) and synthesizing information (54\%) were the two tasks where a majority predicted that $\mathrm{Al} / \mathrm{ML}$ could fully replace human psychiatrists. Female- and US-based doctors were more uncertain that the benefits of Al would outweigh risks than male- and non-US doctors, respectively. Around one in 2 psychiatrists did however predict that their jobs would be substantially changed by $\mathrm{Al} / \mathrm{ML}$.

Conclusions: To our knowledge, this is the first global survey to seek the opinions of physicians on the impact of autonomous $\mathrm{Al} / \mathrm{ML}$ on the future of psychiatry. Our findings provide compelling insights into how physicians think about Al/ML which in turn may help us better integrate technology and reskill doctors to enhance mental health care. 


\section{Introduction}

Mental health disorders are estimated to affect $10-15 \%$ of the population and are among the leading causes of morbidity and mortality worldwide $(1,2)$. By 2030 , this health burden is forecast to cost the global economy some $\$ 16$ trillion (1). Suicide is the second or third leading cause of death among youth in most countries (1). Mental disorders of aging are also on the rise with the numbers of people with dementia expected to triple in coming decades. Stigma, low funding, and an acute shortage of mental health professionals $(1,2)$ are some of the key barriers to addressing global mental health needs. In the US, one estimate showed that $77 \%$ of counties are underserved by psychiatrists (3). In developing countries, the situation is worse - the World Health Organization estimates the rate of psychiatrists in low income countries is some 100 times lower than that in high income countries (2). India, with a population of 1.3 billion, has only about 9,000 psychiatrists (4). Addressing these large diagnostic and treatment gaps is a global public health priority $(1,2)$.

Against these challenges, the rapid spread of smartphones, wearable sensors, cloud based computing and intelligent technologies has led to unprecedented opportunities for patient self-monitoring, and scaling access to health care - and millions of people are already turning to such technologies $(1,5-15)$. The rapid pace of deep learning advances has led some experts to predict that Al is poised to disrupt healthcare and the work of doctors $(6,11$, reviewed in 9$)$. Deep learning systems can already match or outperform radiologists and pathologists in diagnostic accuracy, under controlled settings (9). Indeed, some technology futurists argue that advancements in Al/ML may one day obviate the need of physicians altogether $(7,11)$. Other informaticians and $\mathrm{Al}$ 
experts are less sanguine, forecasting that the role of doctors can never be fully replaced, and that the future of medicine will likely become a "team sport" between humans and machines $(10,13)$. Consistent with the latter view, a labor market report from Oxford University predicted that while $47 \%$ of total US employment was at risk for substitution by intelligent technology over the next two decades, the work performed by doctors would be at lower risk for automation (16). This view is also shared by authors of a more recent working paper from the Office of Economic Cooperation and Development (17) which looked at skills data from over 30 countries.

Despite lively and ongoing debate, limited attention has been paid to the views of practicing physicians on the impact of Al on medical professions. This is especially relevant in mental health care which depends on long-term, empathetic relationships between physicians and highly vulnerable patients, and in light of the flood of mental health apps available for download.

In this survey, we sought to investigate the opinions of psychiatrists about the impact of autonomous intelligent technologies, referred to as $\mathrm{Al} / \mathrm{ML}$, on the future of their jobs, as well as their potential risks and benefits in the context of mental health.

\section{Methods}

\section{Study sample}

The survey and data analyses were conducted in Spring/Summer of 2019. This was a cross-sectional global survey of psychiatrists registered with Sermo, a secure digital (online) platform designed for physician networking and anonymous survey research. 
The platform is exclusive to verified and licensed physicians and has over 800,000 registered physicians, of all specialties, worldwide. The survey randomly sampled registered psychiatrists to get representation from the US, Europe and the rest of the world. As such this was an exploratory study and we aimed for a target sample size of approximately 750 psychiatrist respondents, to approximate a prior report (18). The survey collected information on nationality, demographics, perceptions of the future of psychiatry; perceptions of the workforce; and practice characteristics. The anonymous survey results were de-linked to respondent's personal identifiable information to create de-identified data. This research does not include any sensitive or identifiable data in agreement with Duke University's institutional review board requirements for exempt research.

\section{Survey instrument}

We used an instrument previously shown to have utility $(18,19)$ and modified it for this survey to include 10 questions specifically geared to key tasks that are a routine part of a psychiatrist's role. The questions were included after consultations with psychiatrists and initial piloting to ensure face validity and feasibility.

As this was a global survey, the 10 tasks were universal to psychiatrists across different countries and different types of health systems. The tasks included: 1) provide documentation (e.g. update medical records) about patients, 2) perform a mental status examination, 3) interview psychiatric patients in a range of settings to obtain medical history, 4) analyze patient information to detect homicidal thoughts, 5) analyze patient information to detect suicidal thoughts, 6) synthesize patient information to reach 
diagnoses, 7) formulate personalized medication and/or therapy treatment plans for patients, 8) evaluate when to refer patients to outpatient versus inpatient treatment, 9) analyze patient information to predict the course of a mental health condition (prognoses), and 10) provide empathetic care to patients. Task descriptions employed neutral language that was not biased in favor of either human physicians or technology.

To avoid potential ambiguities in how respondents interpreted the questions and response options, we focused on whether tasks were likely to be fully - rather than partially - outsourced to technology. We also aimed to allow respondents to express discriminatory opinions about the tasks they considered most (or indeed least) vulnerable to replacement by machine learning. Finally, because the term "machine learning" may be unfamiliar among some physicians and considered too narrow a description among medical Al researchers, we employed generic language such as "machines" and "technology" to refer to Al innovations.

The first set of ten items opened with a brief statement: "Some people believe that current and future innovations in artificial intelligence will lead to significant changes in psychiatric practice and that machines will one day replace the work of psychiatrists. Others deny that new technologies will ever have the capacity to replace this work". We then asked respondents their opinion on the likelihood that "future technology will be able to fully replace and not merely aid human doctors in performing each task as well as or better than the average Psychiatrist." Employing 6-level Likert items we included the following response options: "extremely unlikely", "unlikely", "somewhat unlikely", "somewhat likely", "likely, and "extremely likely". We avoided "don't know", "neutral" or "no opinion" options on the grounds that respondents often conflate these answers (20). 
Furthermore, inclusion of these choices may have precluded measurement of substantive opinions among psychiatrists: research indicates that this is a risk in selfadministered questionnaires where time-pressured individuals may invest less effort in their answers (21). Participants who responded that replacement was "somewhat likely", "likely" or "extremely likely" were asked a follow-up question about how soon in their estimation technology would have the capacity to perform the task and provided with a list of five response options (0-4 years from now, 5-10 years, 11-25 years, 25-50 years, more than 50 years from now).

\section{Data and Statistical methods}

The de-identified data was analyzed to extract summary statistics and $95 \%$ confidence intervals. Descriptive statistics were used to examine physicians' characteristics and opinions about the likelihood of future technology replacing doctors on the ten key psychiatric tasks. We also collapsed into positive (for "somewhat likely", "likely" or "extremely likely" responses) versus negative (for "somewhat unlikely", "unlikely" or "extremely unlikely") opinions for some contrasts. Contrasts whose $95 \% \mathrm{Cls}$ did not overlap were viewed as qualitatively different.

\section{Results}

\section{Sample characteristics}

Table 1 summarizes the demographic characteristics. The final respondent sample consisted of 791 psychiatrists representing 22 countries in North and South America, 
Europe, and Asia-Pacific (Table 2). About $40 \%$ of the participating physicians were under the age of 44 years and another $34 \%$ were over the age of 55 . Women comprised about $30 \%$ of the sample. About two-thirds (64\%) were white with the rest describing themselves as Asian, Black, Hispanic or mixed. Participants worked in public clinics (52\%), private practice (35\%) and academia (13\%). Most reported seeing more than 10 patients per average day.

\section{Opinions about Al/technological replacement of physician jobs}

About $48.7 \%$ of respondents felt that $\mathrm{Al} / \mathrm{ML}$ would have no influence or only minimal influence on the future work of psychiatrists over the next 25 years (Figure 1). Only $3.8 \%$ of respondents felt it was likely that future technology would make their jobs obsolete. Another $47 \%$ predicted that their jobs would be moderately changed by $\mathrm{Al} / \mathrm{ML}$ over the next 25 years (Figure 1).

\section{Opinions about Al/technological replacement of specific psychiatric tasks}

Results for the 10 specific psychiatric tasks are shown in Tables 3 and 4 . Most respondents (83\%) felt it unlikely that future technology would ever be able to provide empathic care as well as or better than the average psychiatrist. Likewise, most psychiatrists considered it unlikely that future technology could ever fully replace psychiatrists for mental status examinations (67\%), evaluating acute homicidal thoughts $(58 \%)$, interviewing patients in a range of settings to obtain medical history $(58 \%)$, deciding whether to refer to inpatients versus outpatient treatment (55\%), formulating personalized patient treatment plans $(53 \%)$ or evaluating suicidal thoughts $(52 \%)$. 
In contrast, the majority of respondents (83\%) judged it likely that future technology would be able to replace human physicians on the task of documentation (e.g. update medical records). Almost half (47\%) predicted that such wherewithal would emerge in the next four years, with an additional $37 \%$ giving an estimate of 5 to 10 years from now (Figure 2). Further, a slim majority (54\%) believed it likely that future technology would be able to fully replace human physicians when it comes to synthesizing information to reach diagnoses. About (32\%) predicted that such wherewithal would emerge in the next four years, with an additional $41 \%$ giving an estimate of 5 to 10 years from now (Figure 3). Table 5 depicts the timeline predicted by psychiatrists for Al/ML capacity to emerge to replace them on each specific psychiatric task.

\section{Opinions on Potential Benefits and Risks of Future Technologies/Al}

The risk benefit judgments also varied by physician gender and practice location. Among all respondents, $40 \%$ said they were uncertain that the potential benefits of Al/ML would outweigh the possible risks/harms and another $25 \%$ said the potential benefits would not outweigh the possible risks (Figure 4). Only $36 \%$ felt that the potential benefits of future $\mathrm{Al} / \mathrm{ML}$ would outweigh the possible risks in their field.

Female psychiatrists (48\%) were more likely to be uncertain that the benefits of $\mathrm{Al} / \mathrm{ML}$ in psychiatry would outweigh the risks than male psychiatrists (35\%). Only $23 \%$ of women predicted that the benefits of Al would outweigh the possible risks compared to $41 \%$ of men (Figure 5). 
Likewise, US-based (46\%) were more likely to be uncertain that the benefits of $\mathrm{Al} / \mathrm{ML}$ in psychiatry would outweigh the risks than those in Europe (37\%) or rest of the world (32\%). Only $30 \%$ of US-based psychiatrists predicted that the potential benefits of future technologies/Al would outweigh the possible risks (Figure 6).

\section{Predictions about how Al/ML technologies could help or harm clinical care}

Respondents were also invited to submit open ended qualitative comments to elaborate on their survey choices. These qualitative comments will be the subject of a separate article but selected comments are presented here to illustrate the level of insights.

Potential benefits of Al/ML noted (Table 6) include "eliminating human error", work under any environment", "standardization and personalization of care plans", "more efficient integration of big data", "scalability of treatment will be a big help where there is a shortage of psychiatrists", "more truthful responses from patients", "training beginner psychiatrists", "streamlining workflow to free up psychiatrist time" and "elucidating etiologies of brain diseases that are currently opaque to humans".

Possible risks/harms (Table 7) identified include "lack of empathy", "will remain a thing and not a person", "feelings of antipathy due to job displacement", "less privacy and more fatalism", "not sure how talking to Al would help stigma", "won't be able to assess mental status comprehensively", "greater burnout if administrators use Al to increase workload", and "physicians will forsake creative thinking". 


\section{Discussion}

The World Economic Forum's 2019 report titled "Empowering 8 Billion Minds" highlighted that "the burden of mental illness, in terms of human suffering, is both catastrophic and growing" and that "in the 36 largest countries where treatment is not accessible to everyone, mental health conditions have resulted in over 12 billion days of lost productivity" (2). It noted that mental health focused apps are among the fastest growing sectors in the global digital health market and called for the adoption of technologies, in an ethical, empathetic and evidence based manner, to enable better mental health for all (2).

In that context, our survey provides the first global insight into how practicing psychiatrists think about the possible benefits and risks of future intelligent technologies in mental health care as well as how Al may impact their own jobs. Several key findings emerged. While about 1 in 2 psychiatrists believed that AI/ML would substantially change their jobs, only $3.8 \%$ felt that it would make their jobs obsolete. Our survey also revealed that doctors were skeptical that future technologies could perform most complex psychiatric tasks as well as or better than human doctors. In particular, an overwhelming majority (83\%) of respondents felt it unlikely that future technology would ever be able to provide empathic care as well as or better than the average psychiatrist. The mental status examination, evaluation of dangerous behavior and formulation of a personalized treatment plan, all essential roles of a psychiatrist, were also felt to be tasks that a future $\mathrm{Al} / \mathrm{ML}$ technology would be unlikely to perform as well. 
We speculate there may be several explanations for the skepticism expressed by the doctors. One possibility is they are cautious of the hype around $\mathrm{Al}$ (22), especially given Al's many boom and bust cycles over the past five decades, and placing high value on human interaction and personalized professional analysis. While a growing number of research studies have documented the utility of Al tools for mental health diagnosis and care $(2,9,14)$, we are still far away from an Al that accurately recognizes and understands the full range of human emotions and mental illnesses. Further, unlike pattern-based fields like radiology or pathology where Al can sometimes outperform doctors, psychiatry requires greater integration of cultural and psychosocial factors with medical comorbidities. The contrasting explanation for the survey findings could be that doctors may be overvaluing their skills (9) and/or underestimating the rapid pace of progress in intelligent technologies. If the latter is true, it also raises questions about the preparedness of the profession to navigate technological change in the delivery of patient care $(2,9,11,12,14)$. The range of opinions obtained from respondents suggest that multiple conflicting beliefs and factors may be at play.

The validity of our survey findings is supported by recent research $(16-18,23)$. A highly cited labor market report by Oxford professors Carl Frey and Michael Osbourne looked at the risk of displacement due to automation for 702 occupations (16). They rated the jobs on skills needed such as perception, creative intelligence, social intelligence, empathy, and manual dexterity. While $47 \%$ of the total US labor market was felt to be at risk for job losses, the work of mental health social workers and physicians were felt to be at lower risk (16). A projection of the Office of Economic Cooperation and Development, using data from over 30 countries, also found that physician jobs would 
be at low risk for automation (17). A 2018 UK survey found that family physicians believed it was unlikely that machines could replace them in delivering empathic care (18). A survey which examined Korean doctors' knowledge of Al found that only $35 \%$ agreed that Al could replace doctors in their jobs (23).

Another key insight that emerged from our survey was that a relatively high number of physicians (40\%) were uncertain that the possible benefits of future $\mathrm{Al}$ in mental health would outweigh the possible risks/harms. In particular more female psychiatrists (versus males) and more US psychiatrists (versus those elsewhere) were uncertain that the benefits of Al would outweigh the potential risks. We do not know the reasons for this but there are some speculative possibilities including the fact that doctors may not feel confident in their knowledge of Al and may find it difficult to separate marketing hype from ground truth.

The gender differences in Al risk perception noted in our survey are novel but may be commensurate with a large body of findings that women are more risk averse than men (24). Thus, female psychiatrists may be more cautious and circumspect in weighing up the benefits versus harms of $\mathrm{Al} / \mathrm{ML}$, especially where ambiguities persist with respect to ethics, biases, inequities, data privacy and risks of poorly validated "black box" algorithms $(2,10,25)$. Unlike European countries which operate with universal health coverage and strict regulations about consumer and citizen data privacy, the US operates on multiple insurance-systems and has substantially weaker data privacy rules. This may be one reason that US health professionals perceive patients to be at graver risk from the sharing of health information gathered by electronic devices and 
continuous online monitoring in being sold to third parties and in determining privateinsurance policies. The EU General Data Protection Regulation (GDPR) gives control to individuals over their personal data and requires businesses to use the highest-possible privacy settings by default. While parallel legislation may come into effect in California in January 2020, no such laws have so far been enacted at a federal level in the USA nor is there much appetite to do so. Lack of legislative movement on citizen protections in respect of health data gathering may have further aroused caution about the benefits of machine learning among vulnerable patients, in the US contexts.

Practitioners based in several middle and lower income countries expressed more optimism than those in the USA about the beneficial impact of AI on professional practice - possibly due to lower access to care in low and middle income settings (1). As a recent report from the World Health Organization noted the shortage of psychiatrists in low income countries is some 100 -fold greater than it is in the wealthy nations (1). The potential for $A \mathrm{I} / \mathrm{ML}$ innovations to optimize efficiency via the provision of cheaper, scalable access to mental health care, may have influenced the views of psychiatrists working in under-resourced health systems, where stigmatization of mental health conditions may also be a key, ongoing consideration.

Last but not least, our survey provides powerful insights from a global sample of psychiatrists - the end users - into how Al/ML could be optimally deployed to work with physicians, rather than replace them, to enhance mental health care. A crucial reason that new technologies fail to be adopted in healthcare is that they often do not take the end user into account. Respondents identified ways that their effectiveness and face 
time with patients could be improved by $\mathrm{Al} / \mathrm{ML}$ as well as several potential risks/harms from future $\mathrm{Al}$ - all of which may be informative to technology developers, regulators, payers and consumers. While doctors were skeptical about the prospects of $\mathrm{Al} / \mathrm{ML}$ replacing them, about one in two psychiatrists felt that future technologies would significantly transform their jobs. Psychiatrists also predicted that $\mathrm{Al} / \mathrm{ML}$ could aid in several ways such as reducing administrative burden, 24/7 monitoring, individualized drug targets to reduce side effects, integration of new streams of data from wearables and genetics, reducing human errors, scaling care to areas with psychiatrist shortage and elucidating brain etiologies that are currently opaque. Concerns and risks identified include loss of privacy, lack of transparency, unknown effects on stigma, incorrect diagnosis or treatment, dehumanization, lack of empathy, greater physician burnout due to higher throughput and loss of control. These findings, which add to those noted by experts $(2,9,10,14,25)$, should be a priority for further research and ethical oversight.

\section{Strengths and Limitations}

This is the first global survey to investigate the opinions of psychiatrists about the impact of $\mathrm{Al}$ on their profession. The survey benefited from a relatively large sample of psychiatrists drawn from diverse practice settings across 22 countries. In addition, employing Sermo, a global platform of verified and licensed physicians, allowed us to recruit frontline practicing psychiatrists. There are some limitations with our survey. First, was the relative absence of respondents from developing nations (such as in Africa), sampling bias (e.g. people registered on a platform), response biases (e.g. degree to which they are interested in topic may have influenced their participation) as 
well as confounding effects of variables not measured. In the absence of a population margin of error estimate, we computed a $95 \%$ confidence interval. We focused on broad psychiatric functions rather than granular subtasks to reduce anthropocentric bias. Lastly, as with many surveys, we cannot determine causality or predictive validity - the impact of machine learning on psychiatry may not be known for decades. Hence, our findings must be interpreted within this context as preliminary. A population survey to replicate and expand on our findings is warranted. Despite such limitations, this global survey provides foundational insights into how psychiatrists think about future technologies in mental health care.

\section{Conclusions}

Future surveys might usefully examine the views of patients, and those suffering from mental illness on the impact of Al on psychiatry and mental health services; and on forecasts among informaticians and Al experts working at the nexus of mental health research and practice. Combined, such insights would collectively help to better develop and validate, and better prepare mental health professionals and patients to implement machine learning technologies to address this most vital challenge to global health and wellbeing.

\section{Acknowledgments}

The authors would like to thank Sermo, especially Peter Kirk and Joanna Molke, for their collaboration. We would also like to express our gratitude to the physicians who participated in this survey and shared their valuable insights. There was no external 
funding support for this study. Dr Doraiswamy has received research grants from and/or served as an advisor or board member to government agencies, technology and healthcare businesses and advocacy groups for other projects in this field. Dr Blease was supported by an Irish Research Council-Marie Skłodowska-Curie Global Fellowship.

\section{References}

1. World Health Organization. (2018). Mental Health Atlas 2017. 1-68.

2. World Economic Forum Global Future Council on Neurotechnologies. (2019). Empowering 8 Billion Minds: Enabling better mental health for all via the ethical adoption of technologies. 1-27.

3. National Council Medical Director Institute. (2017). The Psychiatric Shortage: Causes and Solutions. Washington D.C. National Council for Behavioral Health. 166.

4. Kabir, G., Naveen, K. C., Prabha, C. (2019). Number of psychiatrists in India: Baby steps forward, but a long way to go. Indian Journal of Psychiatry, 61(1), 104-105.

5. Steinhubl S. R., Muse E. D., Topol E. J. (2013). Can mobile health technologies transform health care? JAMA, 310(22), 2395-2396.

6. Hinton G. (2018). Deep learning - A technology with the potential to transform health care. JAMA, 320(11), 1101-1102.

7. Darcy A. M., Louie A. K., Roberts L. W. (2016). Machine learning and the profession of medicine. JAMA, 315(6), 551-552. 
8. Obermeyer Z., Emanuel E. J. (2016). Predicting the future—big data, machine learning, and clinical medicine. The New England Journal of Medicine, 375(13), $1216-1219$.

9. Topol, E. (2019). Deep medicine: how artificial intelligence can make healthcare human again. Basic Books. Hachette UK.

10. Verghese A., Shah N. H., Harrington R. A. (2018). What this computer needs is a Physician: Humanism and AI. JAMA, 2, 319-321.

11. Naylor C. D. (2018). On the prospects for a deep learning health care system. JAMA, 320(11). 1099-2010.

12. Cohen I. G., Graver H. S. (2017). Cops, docs and code. A dialogue between big data in health care and predictive policing. UCDL Rev, 51(437), 437-474.

13. Obermeyer Z., Lee T. H. (2017). Lost in thought - the limits of the human mind and the future of medicine. New England Journal of Medicine, 377(13), 1209-1211.

14. Roberts, L. W., Chan, S., Torous, J. (2018). New tests, new tools: Mobile and connected technologies in advancing psychiatric diagnosis. npj Digital Medicine, 1, $1-4$.

15. Boeldt, D. L., Wineinger, N. E., Waalen, J., Gollamudi, S., Grossberg, A., Steinhubl, S. R, Topol, E. J. et al. (2015). How Consumers and Physicians View New Medical Technology: Comparative Survey. Journal of medical Internet research, 17(9), 215.

16. Frey C. B., Osborne M. A. (2017). The future of employment: how susceptible are jobs to computerization? Technological Forecasting and Social Change, 114, 254280. 
17. Nedelkoska L., Quintini G. (2018). Automation, skills use and training. OECD Social, Employment and Migration Working Papers, 2018. OECD Publishing, Paris, 202, 1124.

18. Blease, C., Bernstein, M. H., Gaab, J., Kaptchuk, T. J., Kossowsky, J., Mandl, K. D., Davis, R. B. and DesRoches, C. M. (2018). Computerization and the future of primary care: A survey of general practitioners in the UK. PloS one, 13(12), 1-19.

19. Blease, C., Kaptchuk, T. J., Bernstein, M. H., Mandl, K. D., Halamka, J. D. and DesRoches, C. M. (2019). Artificial Intelligence and the Future of Primary Care: Exploratory Qualitative Study of UK General Practitioners' Views. Journal of medical Internet research, 21(3), 1-24.

20. Armstrong R. L. (1987). The midpoint on a five-point Likert type scale. Perceptual and Motor Skills, 64(2), 359-362.

21. Krosnick J. A., Holbrook A. L., Berent M. K. et al. (2002). The impact of "no opinion" response options on data quality: non-attitude reduction or an invitation to satisfice? Public Opinion Quarterly, 66(3), 371-403.

22. Strickland, E. (2019). IBM Watson, heal thyself: How IBM overpromised and underdelivered on AI health care. IEEE Spectrum, 56(4), 24-31.

23. Oh S., Kim J. H., Choi S. W., Lee H. J., Hong J., Kwon S. H. (2019). Physician Confidence in Artificial Intelligence: An Online Mobile Survey. J Med Internet Res, 21(3), 1-22.

24. Eckel, C. C., Grossman, P. J. (2008). Men, women and risk aversion: Experimental evidence. Handbook of experimental economics results, 1(7), 1061-1073. 
25. Fiske A., Henningsen P., Buyx A. (2019). Your robot therapist will see you now:

Ethical implications of embodied artificial intelligence in psychiatry, psychology, and psychotherapy. J Med Internet Res, 21(5), 1-12. 
Table 1. Demographics of the Psychiatrists $(\mathrm{N}=791)$

\begin{tabular}{|l|l|}
\hline Gender & $\%$ \\
\hline Male & $69.5 \%$ \\
\hline Female & $29.2 \%$ \\
\hline Prefer not to say & $1.1 \%$ \\
\hline Age & $9.7 \%$ \\
\hline $25-34$ & $29.3 \%$ \\
\hline $35-44$ & $26.7 \%$ \\
\hline $45-54$ & $24.7 \%$ \\
\hline $55-64$ & $9.6 \%$ \\
\hline 65 and above & \multicolumn{2}{|l|}{} \\
\hline Race/ethnicity & $17.6 \%$ \\
\hline Asian & $2.0 \%$ \\
\hline Black/African/Caribbean & $3.7 \%$ \\
\hline Mixed/Multiple Ethnic Groups & $64.3 \%$ \\
\hline White & $3.2 \%$ \\
\hline Other Ethnic Group Not Listed & $9.3 \%$ \\
\hline Prefer not to say & \\
\hline
\end{tabular}


Table 2. Country where the Respondent Psychiatrist Practices

\begin{tabular}{|l|l|l|}
\hline Country & $\mathbf{N}$ & $\%$ \\
\hline UNITED STATES & 276 & $34.9 \%$ \\
\hline FRANCE & 77 & $9.7 \%$ \\
\hline ITALY & 74 & $9.4 \%$ \\
\hline GERMANY & 59 & $7.5 \%$ \\
\hline SPAIN & 57 & $7.2 \%$ \\
\hline UNITED KINGDOM & 50 & $6.3 \%$ \\
\hline RUSSIAN FEDERATION & 30 & $3.8 \%$ \\
\hline AUSTRALIA & 25 & $3.2 \%$ \\
\hline JAPAN & 22 & $2.8 \%$ \\
\hline MEXICO & 20 & $2.5 \%$ \\
\hline CANADA & 18 & $2.3 \%$ \\
\hline GREECE & 15 & $1.9 \%$ \\
\hline CHINA & 14 & $1.8 \%$ \\
\hline BRAZIL & 12 & $1.5 \%$ \\
\hline POLAND & 11 & $1.4 \%$ \\
\hline TURKEY & 11 & $1.4 \%$ \\
\hline NETHERLANDS & 2 & $0.1 \%$ \\
\hline BELGIUM & 3 & $0.4 \%$ \\
\hline SWITZERLAND & 2 & $0.3 \%$ \\
\hline NORWAY & $1.0 \%$ \\
\hline PORTUGAL & $3 \%$ & \\
\hline INDIA & 3 & \\
\hline
\end{tabular}


Table 3. Responses to the question "in your opinion what is the likelihood that future technology will be able to replace human doctors to perform these tasks as well as or better than the average psychiatrist?"

\begin{tabular}{|c|c|c|c|c|c|c|}
\hline \multirow[b]{2}{*}{ Task } & \multicolumn{6}{|c|}{$\begin{array}{c}\text { Opinions } \\
\text { Frequency-percentage } \\
(95 \% \mathrm{Cl})\end{array}$} \\
\hline & $\begin{array}{l}\text { Extremely } \\
\text { unlikely }\end{array}$ & Unlikely & $\begin{array}{l}\text { Somewhat } \\
\text { unlikely }\end{array}$ & $\begin{array}{l}\text { Somewhat } \\
\text { likely }\end{array}$ & Likely & $\begin{array}{l}\text { Extremely } \\
\text { likely }\end{array}$ \\
\hline $\begin{array}{l}\text { Provide documentation (e.g., } \\
\text { update medical records) about } \\
\text { patients }\end{array}$ & $\begin{array}{c}6 \\
(4.3 \text { to } 7.7)\end{array}$ & $\begin{array}{c}8 \\
(6.1 \text { to } 9.9)\end{array}$ & $\begin{array}{c}11 \\
\text { (8.8 to } 13.2)\end{array}$ & $\begin{array}{c}24 \\
(21.0 \text { to } 27.0)\end{array}$ & $\begin{array}{c}24 \\
(21.0 \text { to } 27.0)\end{array}$ & $\begin{array}{c}28 \\
(24.9 \text { to } 31.1)\end{array}$ \\
\hline $\begin{array}{l}\text { Provide empathetic care to } \\
\text { patients }\end{array}$ & $\begin{array}{c}53 \\
(49.5 \text { to } 56.5)\end{array}$ & $\begin{array}{c}19 \\
(16.3 \text { to } 21.7)\end{array}$ & $\begin{array}{c}11 \\
\text { (8.8 to } 13.2)\end{array}$ & $\begin{array}{c}9 \\
(7.0 \text { to } 11.0)\end{array}$ & $\begin{array}{c}5 \\
\text { (3.5 to } 6.5)\end{array}$ & $\begin{array}{c}3 \\
(1.8 \text { to } 4.2)\end{array}$ \\
\hline $\begin{array}{l}\text { Formulate personalized medication } \\
\text { and/or therapy treatment plans for } \\
\text { patients }\end{array}$ & $\begin{array}{c}16 \\
(13.5 \text { to } 18.6)\end{array}$ & $\begin{array}{c}20 \\
(17.2 \text { to } 22.8)\end{array}$ & $\begin{array}{c}17 \\
(14.4 \text { to } 19.6)\end{array}$ & $\begin{array}{c}25 \\
(22.0 \text { to } 28.0)\end{array}$ & $\begin{array}{c}14 \\
(11.6 \text { to } 16.4)\end{array}$ & $\begin{array}{c}8 \\
(6.1 \text { to } 9.9)\end{array}$ \\
\hline $\begin{array}{l}\text { Evaluate when to refer patients to } \\
\text { outpatient versus inpatient } \\
\text { treatment }\end{array}$ & $\begin{array}{c}17 \\
(14.4 \text { to } 19.6)\end{array}$ & $\begin{array}{c}19 \\
(16.3 \text { to } 21.7)\end{array}$ & $\begin{array}{c}19 \\
(16.3 \text { to } 21.7)\end{array}$ & $\begin{array}{c}26 \\
(22.9 \text { to } 29.1)\end{array}$ & $\begin{array}{c}12 \\
(9.7 \text { to } 14.3)\end{array}$ & $\begin{array}{c}7 \\
(5.2 \text { to } 8.8)\end{array}$ \\
\hline $\begin{array}{l}\text { Analyze patient information to } \\
\text { establish prognoses }\end{array}$ & $\begin{array}{c}15 \\
(12.5 \text { to } 17.5)\end{array}$ & $\begin{array}{c}15 \\
(12.5 \text { to } 17.5)\end{array}$ & $\begin{array}{c}19 \\
(16.3 \text { to } 21.7)\end{array}$ & $\begin{array}{c}27 \\
(23.9 \text { to } 30.1)\end{array}$ & $\begin{array}{c}16 \\
(13.5 \text { to } 18.6)\end{array}$ & $\begin{array}{c}8 \\
(6.1 \text { to } 9.9)\end{array}$ \\
\hline $\begin{array}{l}\text { Analyze patient information to } \\
\text { detect acute homicidal thoughts }\end{array}$ & $\begin{array}{c}20 \\
(17.2 \text { to } 22.8)\end{array}$ & $\begin{array}{c}21 \\
(18.2 \text { to } 23.8)\end{array}$ & $\begin{array}{c}17 \\
(14.4 \text { to } 19.6)\end{array}$ & $\begin{array}{c}23 \\
(20.1 \text { to } 25.9)\end{array}$ & $\begin{array}{c}12 \\
(9.7 \text { to } 14.3)\end{array}$ & $\begin{array}{c}6 \\
(4.3 \text { to } 7.7)\end{array}$ \\
\hline $\begin{array}{l}\text { Analyze patient information to } \\
\text { detect suicidal thoughts }\end{array}$ & $\begin{array}{c}18 \\
(15.3 \text { to } 20.7)\end{array}$ & $\begin{array}{c}17 \\
(14.4 \text { to } 19.6)\end{array}$ & $\begin{array}{c}16 \\
(13.5 \text { to } 18.6)\end{array}$ & $\begin{array}{c}25 \\
(21.9 \text { to } 28.0)\end{array}$ & $\begin{array}{c}14 \\
(11.6 \text { to } 16.4)\end{array}$ & $\begin{array}{c}9 \\
(7.0 \text { to } 11.0)\end{array}$ \\
\hline $\begin{array}{l}\text { Synthesize patient information to } \\
\text { reach diagnoses }\end{array}$ & $\begin{array}{c}15 \\
(12.5 \text { to } 17.5)\end{array}$ & $\begin{array}{c}15 \\
(12.5 \text { to } 17.5)\end{array}$ & $\begin{array}{c}16 \\
(13.5 \text { to } 18.6)\end{array}$ & $\begin{array}{c}29 \\
(25.8 \text { to } 32.2)\end{array}$ & $\begin{array}{c}17 \\
(14.4 \text { to } 19.6)\end{array}$ & $\begin{array}{c}9 \\
(7.0 \text { to } 11.0)\end{array}$ \\
\hline $\begin{array}{l}\text { Perform a mental status } \\
\text { examination }\end{array}$ & $\begin{array}{c}27 \\
(23.9 \text { to } 30.1)\end{array}$ & $\begin{array}{c}24 \\
(21.0 \text { to } 27.0)\end{array}$ & $\begin{array}{l}16(13.5 \\
\text { to } 18.6)\end{array}$ & $\begin{array}{c}17 \\
(14.4 \text { to } 19.6)\end{array}$ & $\begin{array}{c}10 \\
(7.9 \text { to } 12.1)\end{array}$ & $\begin{array}{c}6 \\
(4.3 \text { to } 7.7)\end{array}$ \\
\hline $\begin{array}{l}\text { Interview psychiatric patients in a } \\
\text { range of settings to obtain medical } \\
\text { history }\end{array}$ & $\begin{array}{c}24 \\
(21.0 \text { to } 27.0)\end{array}$ & $\begin{array}{c}21 \\
(18.2 \text { to } 23.8)\end{array}$ & $\begin{array}{c}13 \\
(10.7 \text { to } 15.3)\end{array}$ & $\begin{array}{c}20 \\
\text { (17.2 to } 22.8)\end{array}$ & $\begin{array}{c}14 \\
(11.6 \text { to } 16.4)\end{array}$ & $\begin{array}{c}8 \\
\text { (6.1 to } 9.9)\end{array}$ \\
\hline
\end{tabular}


Table 4. Responses to the question "in your opinion what is the likelihood that future technology will be able to replace human doctors to perform these tasks as well as or better than the average psychiatrist?"*

\begin{tabular}{|c|c|c|}
\hline \multirow[b]{2}{*}{ Task } & \multicolumn{2}{|c|}{$\begin{array}{c}\text { Opinions } \\
\text { Frequency-percentage } \\
(95 \% \text { Cl })\end{array}$} \\
\hline & Unlikely & Likely \\
\hline $\begin{array}{l}\text { Provide documentation (e.g., update medical } \\
\text { records) about patients }\end{array}$ & $\begin{array}{c}25 \\
(22.0 \text { to } 28.0\end{array}$ & $\begin{array}{c}75 \\
\text { (72.0 to } 78.0\end{array}$ \\
\hline Provide empathetic care to patients & $\begin{array}{c}83 \\
(80.4 \text { to } 85.6)\end{array}$ & $\begin{array}{c}17 \\
(14.4 \text { to } 19.6)\end{array}$ \\
\hline $\begin{array}{l}\text { Formulate personalized medication and/or } \\
\text { therapy treatment plans for patients }\end{array}$ & $\begin{array}{c}53 \\
(49.5 \text { to } 56.5)\end{array}$ & $\begin{array}{c}47 \\
(43.5 \text { to } 50.5)\end{array}$ \\
\hline $\begin{array}{l}\text { Evaluate when to refer patients to outpatient } \\
\text { versus inpatient treatment }\end{array}$ & $\begin{array}{c}55 \\
(51.5 \text { to } 58.5)\end{array}$ & $\begin{array}{c}45 \\
\text { (41.5 to } 48.5)\end{array}$ \\
\hline $\begin{array}{l}\text { Analyze patient information to establish } \\
\text { prognoses }\end{array}$ & $\begin{array}{c}49 \\
(45.5 \text { to } 52.5)\end{array}$ & $\begin{array}{l}51 \\
(47.5 \text { to } 54.5)\end{array}$ \\
\hline $\begin{array}{l}\text { Analyze patient information to detect acute } \\
\text { homicidal thoughts }\end{array}$ & $\begin{array}{c}58 \\
(54.6 \text { to } 61.4)\end{array}$ & $\begin{array}{c}42 \\
\text { (38.6 to } 45.4)\end{array}$ \\
\hline $\begin{array}{l}\text { Analyze patient information to detect suicidal } \\
\text { thoughts }\end{array}$ & $\begin{array}{c}52 \\
(48.5 \text { to } 55.5)\end{array}$ & $\begin{array}{c}48 \\
(44.5 \text { to } 51.5)\end{array}$ \\
\hline $\begin{array}{l}\text { Synthesize patient information to reach } \\
\text { diagnoses }\end{array}$ & $\begin{array}{c}46 \\
(42.5 \text { to } 49.5)\end{array}$ & $\begin{array}{c}54 \\
\text { (50.5 to } 57.5)\end{array}$ \\
\hline Perform a mental status examination & $\begin{array}{c}67 \\
(63.7 \text { to } 70.3)\end{array}$ & $\begin{array}{c}33 \\
(29.7 \text { to } 36.3)\end{array}$ \\
\hline $\begin{array}{l}\text { Interview psychiatric patients in a range of } \\
\text { settings to obtain medical history }\end{array}$ & $\begin{array}{c}58 \\
(54.6 \text { to } 61.4)\end{array}$ & $(38.6 \quad$ to 45.4$)$ \\
\hline
\end{tabular}

*The 6 Likert categories have been combined into two categories (likely and unlikely). 
Table 5. Predicted timespan when Al/ML technology will have the capacity to replace human physicians for specific clinical tasks*

\begin{tabular}{|c|c|c|c|c|c|}
\hline \multirow[b]{2}{*}{ Task } & \multicolumn{5}{|c|}{$\begin{array}{c}\text { Predicted timespan } \\
\text { Frequency-percentage } \\
(95 \% \mathrm{Cl})\end{array}$} \\
\hline & $0-4$ years & 5-10 years & $11-25$ years & $26-50$ years & $>50$ years \\
\hline $\begin{array}{l}\text { Provide documentation (e.g., } \\
\text { update medical records) about } \\
\text { patients }\end{array}$ & $\begin{array}{c}47 \\
(42.2 \text { to } 51.8)\end{array}$ & $\begin{array}{c}37 \\
(32.3 \text { to } 41.7)\end{array}$ & $\begin{array}{c}11 \\
(8.0 \text { to } 14.0)\end{array}$ & $\begin{array}{c}3 \\
(1.4 \text { to } 4.7)\end{array}$ & $\begin{array}{c}2 \\
(0.8 \text { to } 3.4)\end{array}$ \\
\hline $\begin{array}{l}\text { Provide empathetic care to } \\
\text { patients }\end{array}$ & $\begin{array}{c}28 \\
(16.9 \text { to } 39.1)\end{array}$ & $\begin{array}{c}36 \\
(24.2 \text { to } 47.9)\end{array}$ & $\begin{array}{c}20 \\
(10.1 \text { to } 29.9)\end{array}$ & $\begin{array}{c}8 \\
(1.3 \text { to } 14.7)\end{array}$ & $\begin{array}{c}8 \\
(1.3 \text { to } 14.7)\end{array}$ \\
\hline $\begin{array}{l}\text { Formulate personalized } \\
\text { medication and/or therapy } \\
\text { treatment plans for patients }\end{array}$ & $\begin{array}{c}35 \\
(27.9 \text { to } 42.1)\end{array}$ & $\begin{array}{c}39 \\
(31.8 \text { to } 46.3)\end{array}$ & $\begin{array}{c}18 \\
(12.3 \text { to } 23.7)\end{array}$ & $\begin{array}{c}6 \\
(2.5 \text { to } 9.5)\end{array}$ & $\begin{array}{c}2 \\
(-0.1 \text { to } 4.1)\end{array}$ \\
\hline $\begin{array}{l}\text { Evaluate when to refer patients } \\
\text { to outpatient versus inpatient } \\
\text { treatment }\end{array}$ & $\begin{array}{c}33 \\
(25.5 \text { to } 40.5)\end{array}$ & $\begin{array}{c}44 \\
(36.1 \text { to } 51.9)\end{array}$ & $\begin{array}{c}14 \\
(8.5 \text { to } 19.6)\end{array}$ & $\begin{array}{c}8 \\
(3.66 \text { to } 12.3)\end{array}$ & $\begin{array}{c}1 \\
(-0.6 \text { to } 2.6)\end{array}$ \\
\hline $\begin{array}{l}\text { Analyze patient information to } \\
\text { establish prognoses }\end{array}$ & $\begin{array}{c}28 \\
(21.6 \text { to } 34.4)\end{array}$ & $\begin{array}{c}49 \\
(41.9 \text { to } 56.1)\end{array}$ & $\begin{array}{c}15 \\
(9.9 \text { to } 20.1)\end{array}$ & $\begin{array}{c}5 \\
(1.9 \text { to } 8.1)\end{array}$ & $\begin{array}{c}3 \\
(0.6 \text { to } 5.4)\end{array}$ \\
\hline $\begin{array}{l}\text { Analyze patient information to } \\
\text { detect acute homicidal thoughts }\end{array}$ & $\begin{array}{c}37 \\
(29.1 \text { to } 44.9)\end{array}$ & $\begin{array}{c}40 \\
(31.9 \text { to } 48.1)\end{array}$ & $\begin{array}{c}12 \\
(6.7 \text { to } 17.3)\end{array}$ & $\begin{array}{c}8 \\
(3.5 \text { to } 12.5)\end{array}$ & $\begin{array}{c}3 \\
(0.2 \text { to } 5.8)\end{array}$ \\
\hline $\begin{array}{l}\text { Analyze patient information to } \\
\text { detect suicidal thoughts }\end{array}$ & $\begin{array}{c}34 \\
(27.1 \text { to } 40.9)\end{array}$ & $\begin{array}{c}43 \\
(35.8 \text { to } 50.2)\end{array}$ & $\begin{array}{c}13 \\
(8.1 \text { to } 17.9)\end{array}$ & $\begin{array}{c}8 \\
(4.1 \text { to } 11.9)\end{array}$ & $\begin{array}{c}2 \\
(0 \text { to } 4.0)\end{array}$ \\
\hline $\begin{array}{l}\text { Synthesize patient information to } \\
\text { reach diagnoses }\end{array}$ & $\begin{array}{c}32 \\
(25.6 \text { to } 38.4)\end{array}$ & $\begin{array}{c}41 \\
(34.3 \text { to } 47.7)\end{array}$ & $\begin{array}{c}19 \\
(13.6 \text { to } 24.4)\end{array}$ & $\begin{array}{c}5 \\
(2.0 \text { to } 8.0)\end{array}$ & $\begin{array}{c}3 \\
(0.7 \text { to } 5.3)\end{array}$ \\
\hline $\begin{array}{l}\text { Perform a mental status } \\
\text { examination }\end{array}$ & $\begin{array}{c}31 \\
(23.0 \text { to } 39.0)\end{array}$ & $\begin{array}{c}41 \\
(32.5 \text { to } 49.6)\end{array}$ & $\begin{array}{c}18 \\
(11.3 \text { to } 24.7)\end{array}$ & $\begin{array}{c}9 \\
(4.0 \text { to } 14.0)\end{array}$ & $\begin{array}{c}2 \\
(-0.4 \text { to } 4.4)\end{array}$ \\
\hline $\begin{array}{l}\text { Interview psychiatric patients in a } \\
\text { range of settings to obtain } \\
\text { medical history }\end{array}$ & $\begin{array}{c}27 \\
\text { (20.4 to } 33.6)\end{array}$ & $\begin{array}{c}45 \\
(37.6 \text { to } 52.4)\end{array}$ & $\begin{array}{c}20 \\
(14.1 \text { to } 25.9)\end{array}$ & $\begin{array}{c}6 \\
(2.5 \text { to } 9.5)\end{array}$ & $\begin{array}{c}2 \\
(-0.1 \text { to } 4.1)\end{array}$ \\
\hline
\end{tabular}

\footnotetext{
*question only asked of respondents who felt future $\mathrm{Al} / \mathrm{ML}$ would likely replace them on that task
} 
Table 6. Physicians' comments about the potential benefits of Al/ML in Psychiatry*

"It can work under any environment, no fatigue and not moody." "Al can be more easily controlled than us"

"Eliminate the human error; Less medical errors, more standardized protocols, better outcomes."

"Better quality of life for psychiatrist if work is streamlined. This will lead to either increase in productivity or increase in free time."

"The patient can answer more truthfully to artificial intelligence and to accept the encouragementsupport more objectively."

"Making standardized plans and doing standard assessments."

"Less bias due to race or gender, can use big data more efficiently than humans."

"It might help patients at risk seek care sooner."

"It will be of great benefit in areas where there is shortage of psychiatrists. Scalability of treatment."

"Providing practical guidance for beginners psychiatrists."

"Al will also help us elucidate etiologies of brain diseases that are currently opaque to us."

"The major question appears to be whether society will tolerate use of Al as medical practitioner, rather than whether it is capable of doing..."

*selected to illustrate the range of opinions 
Table 7. Physicians' comments about the potential harms of Al/ML in Psychiatry*

"Lack of empathy/no humanity would jeopardize therapeutic process." "Empath may be a specific job title down the road..someone who works with an Al."

"There may be feelings of antipathy toward Al/tech due to job displacement."

"Al won't be able to assess patient's mental status comprehensively, and therefore will be unable to determine the exact problem."

"There is a possibility that the process for the machine to reach a diagnosis could turn into a black box process, ..beyond human understanding."

"There is a stigma associated with mental health treatment already and am not sure how talking to an Al would help the treatment process at all."

"Until the machine is aware of simulating consciousness, even perfectly it will not eliminate the pain of loneliness. Al will remain a thing, not a person"

"A potential harm is patients having less privacy and more fatalism in general."

"If the time saved is used (by administrators) to increase psychiatrists' patient loads, it might lead to greater burnout."

"Risks of worsening dehumanization and worsening some delirious symptoms"

"Physicians will forsake creative clinical thinking."

*selected to illustrate the range of opinions 
Figure 1. Predicted impact of future Al/ML on the work of psychiatrists over the next 25 years*

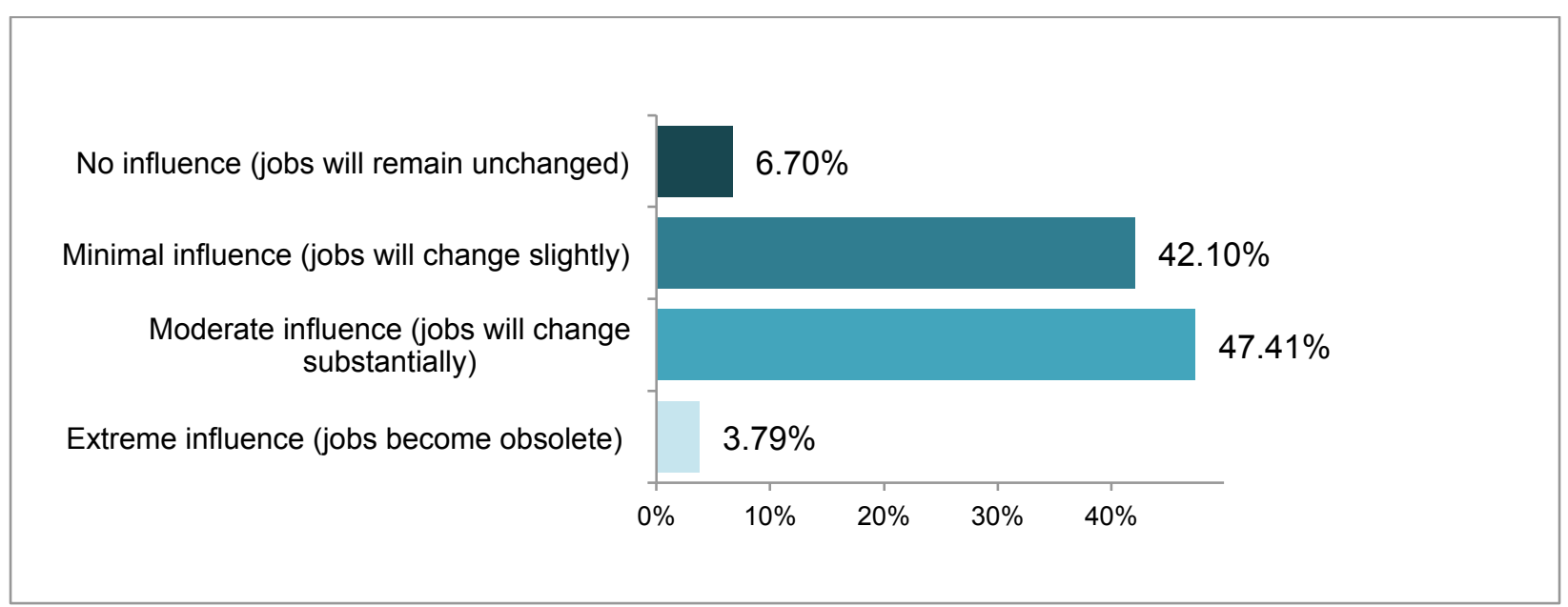

${ }^{*}$ percentages may not add up to $100 \%$ due to rounding

Figure 2. Physicians' opinions on when technology will have the capacity to replace the average psychiatrist in providing documentation about patients*

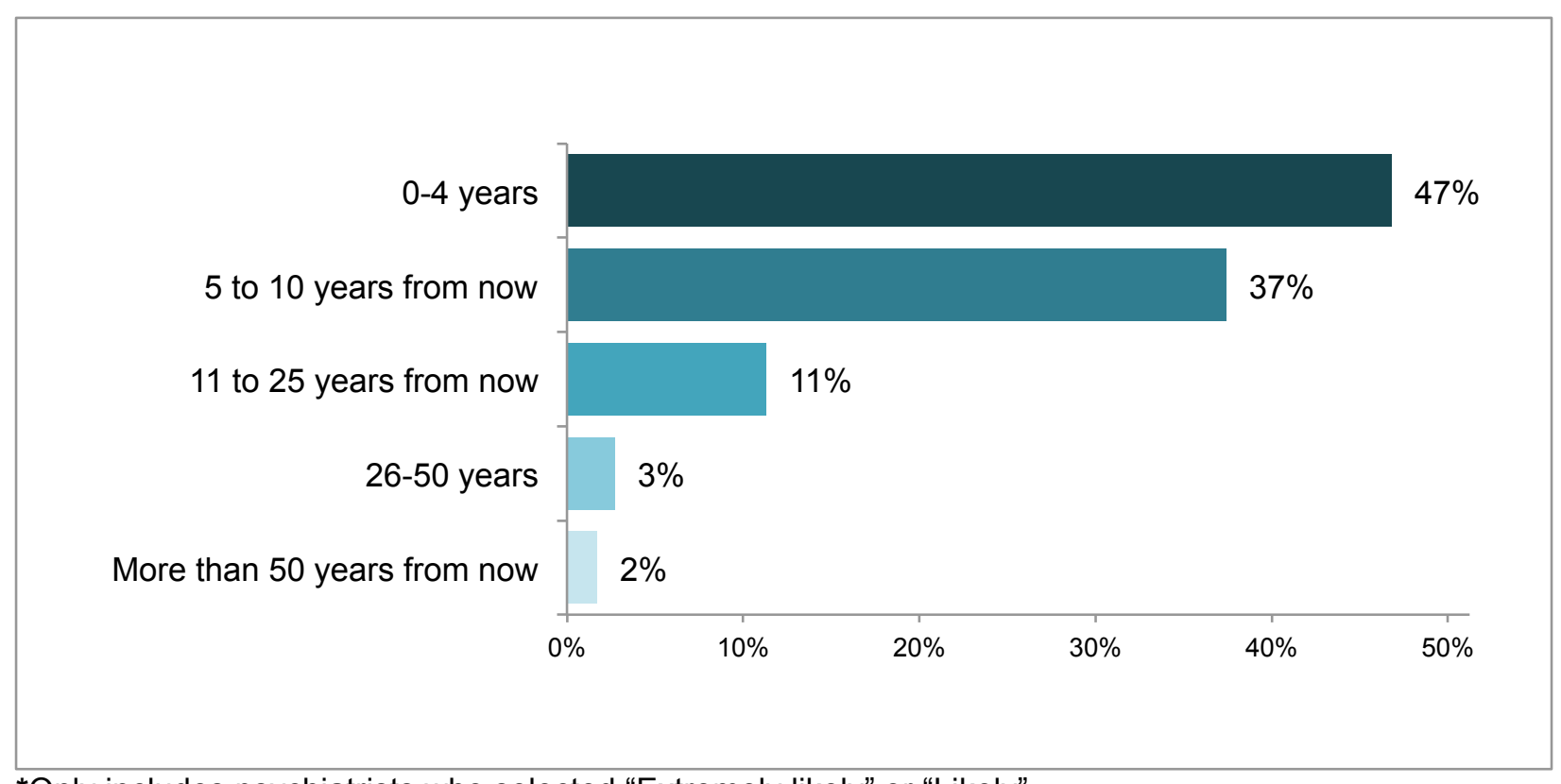

*Only includes psychiatrists who selected "Extremely likely" or "Likely" 
Figure 3. Physicians' opinions on when technology will have the capacity to replace the average psychiatrist in synthesizing patient information to reach diagnosis ${ }^{*}$

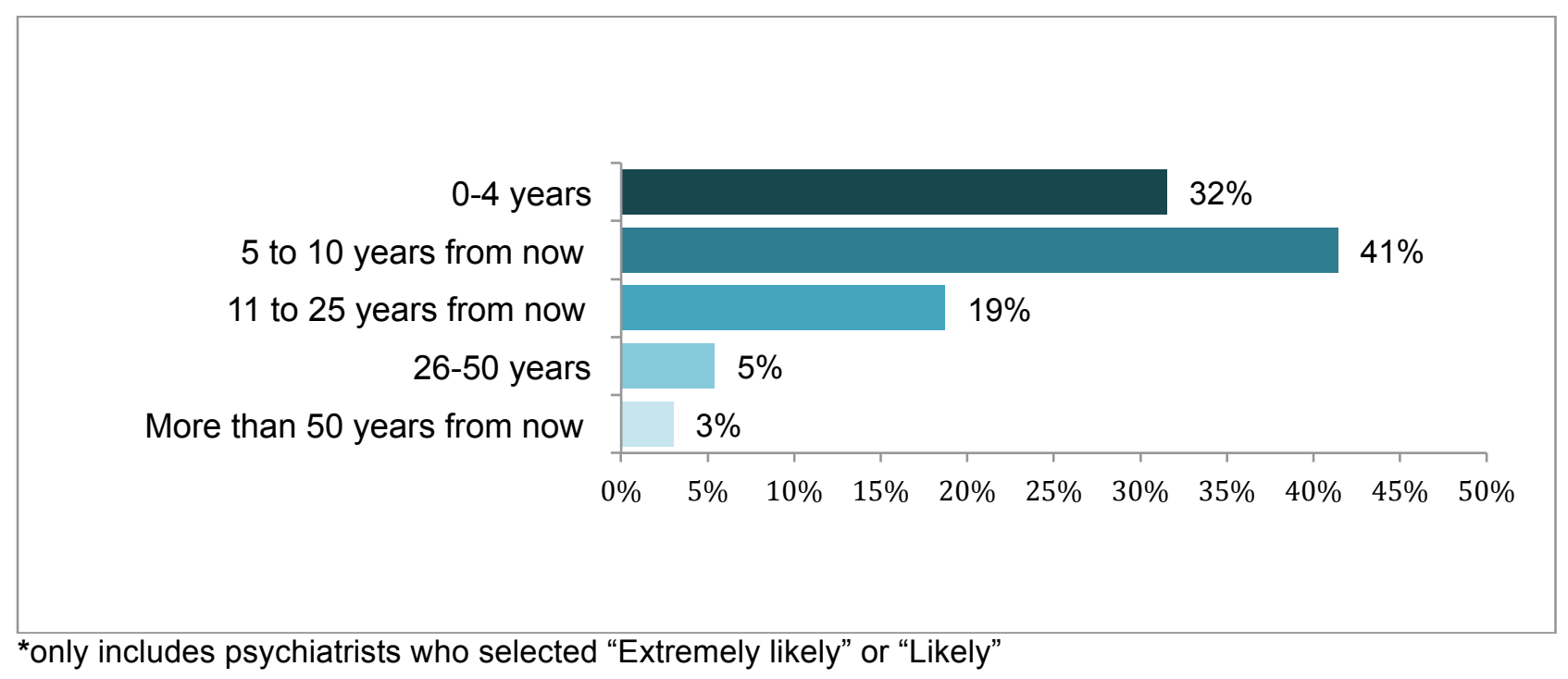

Figure 4. Psychiatrists' opinions on whether potential benefits of Al outweigh possible risks/harms

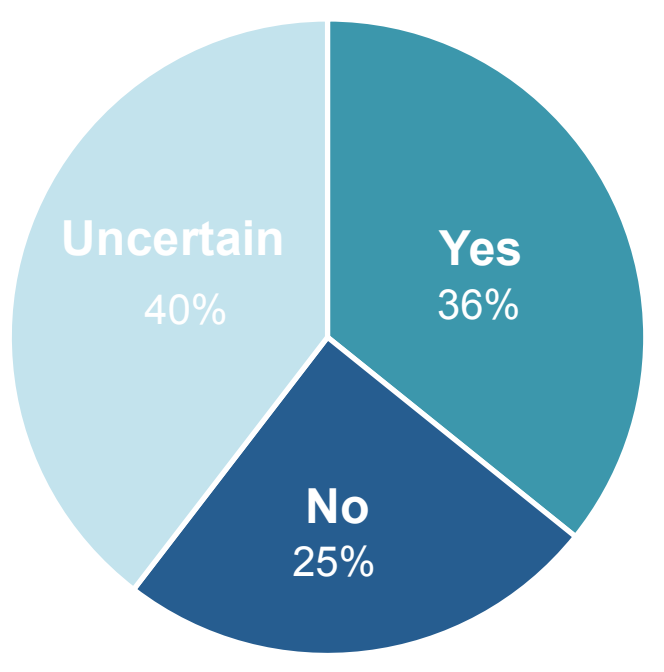

* percentages may not add up to $100 \%$ due to rounding. 
Figure 5. Psychiatrists' opinions on whether potential benefits of Al outweigh possible risks/harms

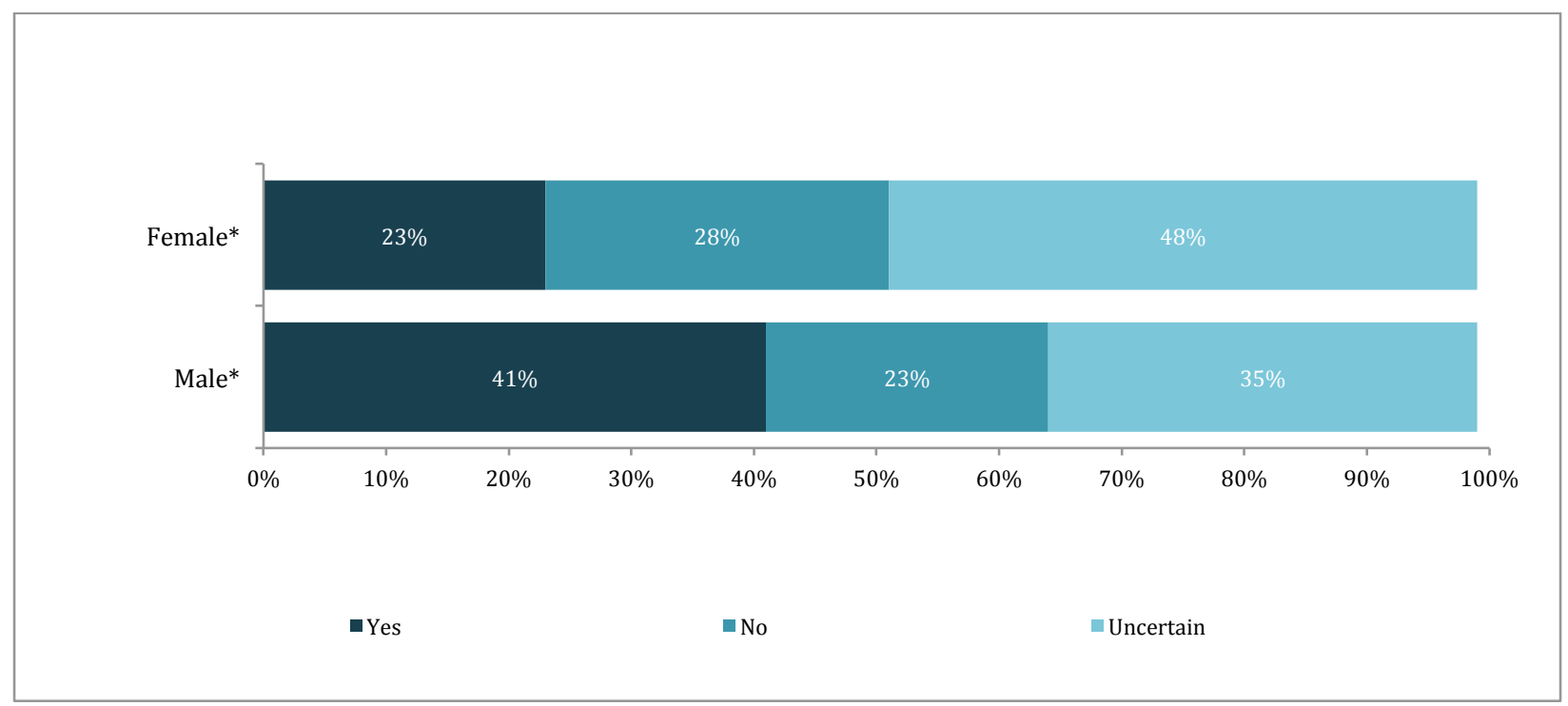

"data shown by gender, percentages may not add up to $100 \%$ due to rounding; some subjects did not mark gender.

Figure 6. Psychiatrists' opinions on whether potential benefits of Al outweigh possible risks/harms ${ }^{*}$

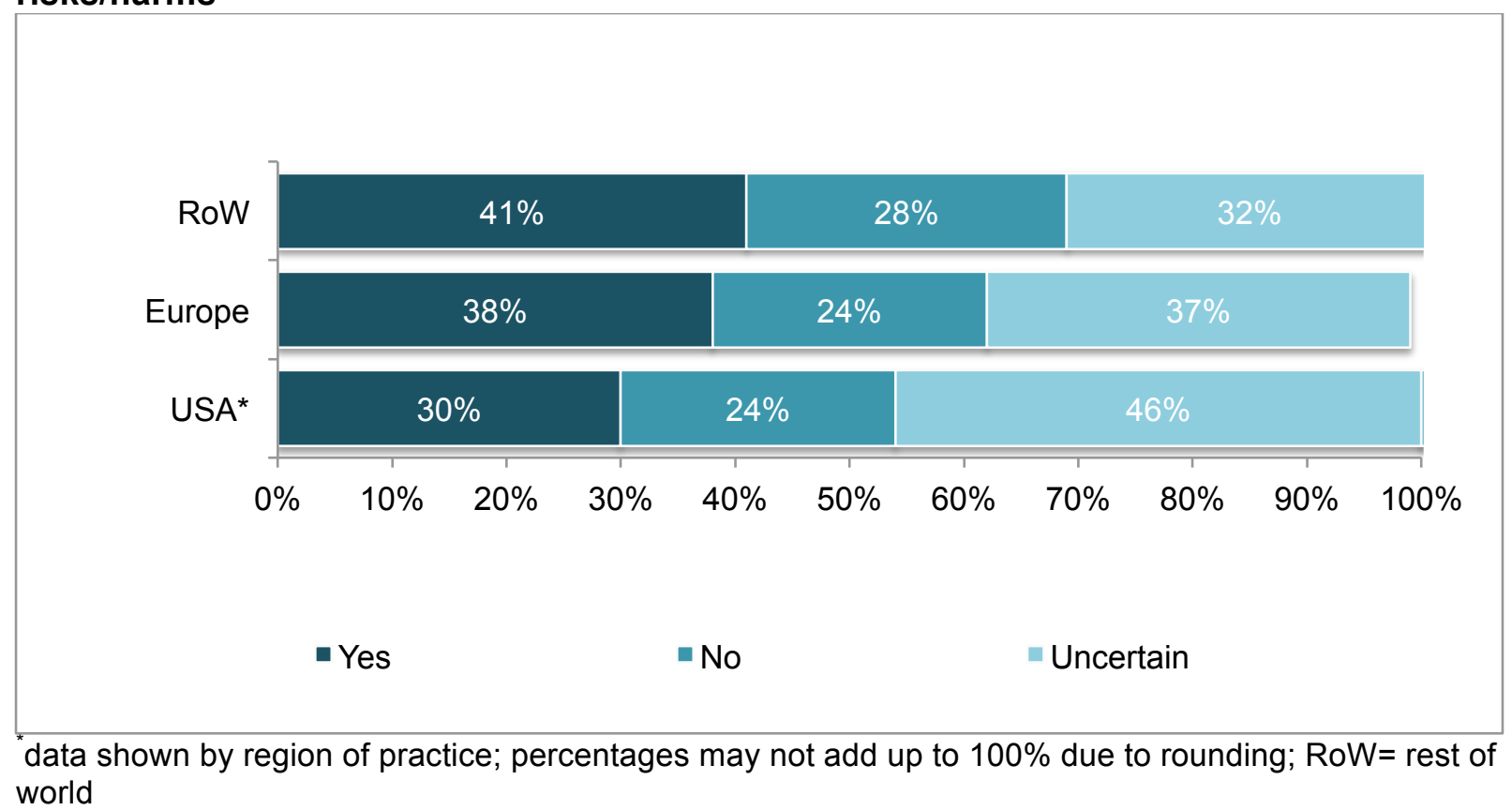

